\title{
A história e o audiovisual em tempos de ditadura
}

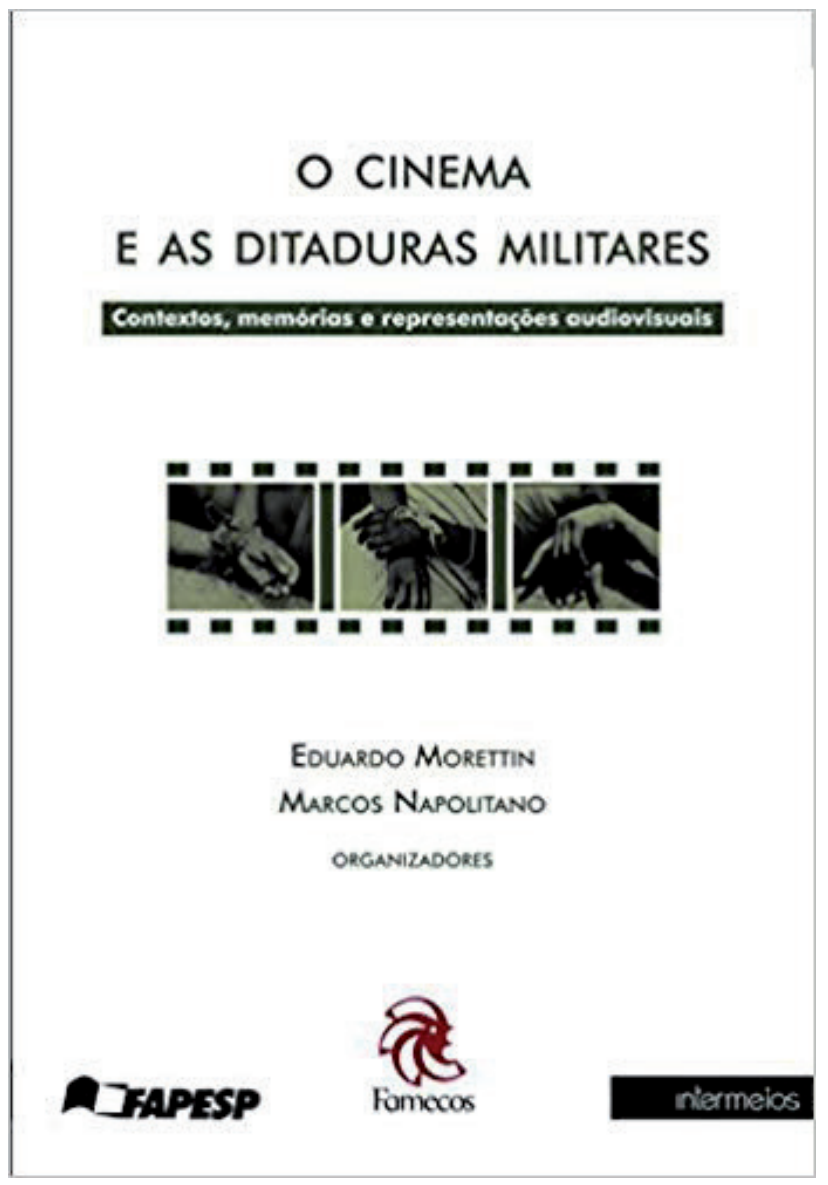

\section{Rodrigo Archangelo}

Doutor em História Social pela Universidade de São Paulo (USP). Pesquisador da Cinemateca Brasileira. Autor de Um bandeirante nas telas: o discurso adhemarista em cinejornais. São Paulo: Alameda Editorial, 2015. rarchangelo03@gmail.com 


\title{
A história e o audiovisual em tempos de ditadura
}

History and audiovisual in times of dictatorship

\author{
Rodrigo Archangelo
}

MORETTIN, Eduardo e NAPOLITANO, Marcos (orgs.). O cinema e as ditaduras militares: contextos, memórias e representações audiovisuais. São Paulo: Intermeios, 2018, 232 p.

Brasil, 31 de março de 2019. Passados 55 anos da mais traumática ruptura democrática em nossa história republicana, o golpe civil-militar de 1964 nunca esteve tão presente. Qualquer discussão sensata sobre o país, hoje, depara-se com o negacionismo (fenômeno mundial, diga-se) que entrou pela porta da frente no último e polêmico pleito eleitoral, e vem retroalimentando um projeto de governo que ameaça avanços estabelecidos pela Constituição de 1988, assim como conquistas democráticas anteriores. Vivemos momentos de luta pela garantia de direitos, de disputa política acerca de quem somos e de defesa do próprio estatuto da História. ${ }^{1}$ Nessa conjuntura, compreender a construção da(s) memória(s) sobre os períodos

${ }^{1}$ Enquanto campo do conhecimento, da pesquisa acadêmica à disciplina ensinada nas escolas. Diante dessa urgência, o $30^{\circ}$ Simpósio Nacional de História da Anpuh discute a "História e o futuro da educação no Brasil", preocupando-se com o ensino de História no atual contexto e nos embates enfrentados por seus profissionais nos espaços escolares, universitários e centros de memória e pesquisa; assim como a "onda conservadora" e os usos do passado autoritário no momento presente.

${ }^{2}$ Concretamente, o telegrama diplomático do governo federal enviado à Comissão de Direitos Humanos da ONU, em 3 de abril de 2019, justificando a tentativa de celebração dos 55 anos da data ao negar a existência de um golpe de estado em 31 de março de 1964. Também vale lembrar o Decreto 9.759 de 11 de abril de 2019, que inviabiliza a existência do Grupo de Trabalho de Perus, responsável pela identificação de desaparecidos políticos entre as ossadas da vala comum do Cemitério de Perus, em São Paulo. autoritários já vividos torna-se vital, mais ainda diante das deliberadas ações institucionais de negação do passado. ${ }^{2}$

Em face dos enfrentamentos cada vez mais urgentes no cenário de disputa por narrativas, o cinema, na intricada relação do audiovisual com a história, cumpre importante papel de transmitir e criar conhecimento, seja como manifestação cultural e artística ou instrumento de reflexão política da realidade. Ao observar essa perspectiva analítica e o atual momento brasileiro, o livro $O$ cinema e as ditaduras militares: contextos, memórias e representações audiovisuais, lançado no final de 2018, traz relevantes contribuições para os dias correntes.

Coletânea com dez artigos de pesquisas independentes, a obra aborda o potencial do audiovisual enquanto articulador do saber histórico, através de dimensões da história pública e da memória social das ditaduras no Brasil, Chile e Argentina, efetivamente apresentadas em obras ficcionais e em documentários, canônicos ou não. Assim, os textos podem (e devem) ser apreciados em seu conjunto, enquanto um guia para a compreensão do audiovisual nas disputas por narrativas históricas - sobretudo a das ditaduras militares, atualmente envoltas pelo mais escancarado discurso negacionista. As pesquisas reunidas no livro trazem reflexões sobre como a atividade e as linguagens do audiovisual ultrapassam a qualidade de condutoras da memória, sendo construtoras de novas memórias e do próprio conhecimento sobre a história, demonstrando quão essencial é a conexão entre cinema e história para se pensar e atuar no tempo presente.

O cinema e as ditaduras militares resulta da seguinte empreitada: o projeto "Cinema e história no Brasil: estratégias discursivas do documentário 
na construção de uma memória sobre o regime militar". ${ }^{3}$ A qualidade dos trabalhos, porém, é tributária do histórico mais amplo de estudos e debates obtido no convívio do grupo CNPq História e Audiovisual: circularidades e formas de comunicação. Criado em 2005 pelos próprios organizadores do livro - os historiadores e professores Eduardo Morettin (ECA-USP) e Marcos Napolitano (FFLCH-USP) -, esse grupo acompanha e fomenta reflexões valiosas para o exame da relação "história e audiovisual" em circuitos acadêmicos nacionais e internacionais. ${ }^{4}$ Nota-se, daí, que alguns artigos foram preparados para o escopo do livro, enquanto outros são desdobramentos de pesquisas anteriores a ele, feitas por especialistas que se dedicam, há tempos, sobre a relação do audiovisual e as ditaduras no Brasil e na América Latina. O livro apresenta forte complementariedade entre as abordagens, ao mostrar coesão amadurecida ao longo das discussões do referido grupo de estudo, que procura valorizar o audiovisual como documento central no âmbito da pesquisa histórica. As abordagens, no todo, levam em conta a linguagem e o diálogo do audiovisual com debates historiográficos, além do seu confronto com as memórias, dominante ou não, das ditaduras estudadas.

Do subtítulo "contextos, memórias e representações audiovisuais" é a "memória em disputa" o leitmotiv presente tanto nos capítulos sobre a produção e os controles burocráticos como nos que esmiúçam as representações audiovisuais. Para educadores e pesquisadores, e o público leitor em geral, vale destacar que as reflexões partem de determinantes estéticas, ideológicas e conjunturais das atividades audiovisuais pesquisadas. Entre os temas analisados estão: projetos e políticas oficiais para o cinema nos anos da ditadura; as opções temáticas e ideológicas nas abordagens do período ditatorial no cinema e televisão; a reflexividade expressa no documentário e a representação de condicionantes históricas na obra ficcional. Aspectos e contextos do audiovisual intrínsecos à construção do saber histórico, e que se entrecruzam nos dez capítulos, como veremos a seguir. Já as filmografias apresentadas e seus contextos mostram o "transitar" da memória desde o aspecto subjetivo dos documentaristas - onde ganham espaço o revisionismo e a problematização do passado - até a construção da memória social mais ampla pelo drama na ficção- com ênfase na perspectiva de uma conciliação entre grupos antagônicos. Alguns capítulos trazem justamente as ramificações desse "transitar", tanto na comparação de obras audiovisuais específicas como na análise de conjuntos representativos.

No levantamento (inédito) das opções temáticas e ideológicas nas produções ficcional e documental sobre a ditadura brasileira, realizado por Marcos Napolitano e Fernando Seliprandy, o transitar da memória emerge. Temáticas como: os "dois demônios", a "inocência juvenil", o "enfoque das vítimas", o "isolamento da luta armada" (e sua "monumentalidade") e a "luta continua" parecem convergir para a resistência democrática da sociedade civil, numa matriz de memória bastante ambígua na conciliação com os que apoiaram o golpe de 1964. Os autores demonstram na decupagem do longa-metragem Paula, a história de uma subversiva (Francisco Ramalho Jr., 1979), as tensões presentes no "grau zero" da memória hegemônica da resistência democrática no cinema. No contexto da reabertura, esse grau zero já trazia as contradições entre o passado recente e a conciliação incômoda diante das expectativas democráticas para o futuro. A partir daí, apontamse temáticas decorrentes dos conflitos políticos e ideológicos da sociedade brasileira no século XXI, principalmente na produção documental, onde
${ }^{3}$ Apoiado pelo CNPq e desenvolvido entre 2014 e 2016, os organizadores informam que o projeto também engendrou atividades como seminários, mostra de filmes, apresentação de trabalhos em congressos científicos e em publicações, o levantamento bibliográfico e o estabelecimento de uma filmografia sobre o tema, disponíveis em $<$ http://historiaeaudiovisual.weebly.com/>.

${ }^{4}$ Além de várias publicações e encontros, podemos citar o seminário temático História, cinema e televisão: lugares de disputa pela memória apresentado nos encontros regionais e nacionais da Anpuh desde 2006, bem como o Colóquio Internacional de Cinema e História, que vai para a $4^{\underline{a}}$ edição em 2019. 
ganharam espaço a memória "íntima e familiar" e o "balanço geracional", a "experiência do exílio" e o "espectro dos desaparecidos", a "contracultura" e o "colaboracionismo civil" (bem pouco tratado, ressalvam os autores).

Na produção televisiva, Mônica Kornis retoma sua pesquisa sobre a construção da memória dos "anos de chumbo", através da minissérie Anos rebeldes (Gilberto Braga, 1992), da Rede Globo de Televisão. A análise dessa paradigmática produção - que se valeu, de forma inovadora, de imagens de arquivo para o aprofundamento diegético - explicita o viés melodramático dispensado à memória hegemônica da resistência. A autora destaca a opção da emissora em ancorar a trama na dimensão individual de jovens da classe-média, com o crivo da autocensura em alguns capítulos, para evocar um passado romantizado da resistência juvenil dos anos sessenta, e se aproximar da vida política nacional e dos "caras pintadas", que se manifestavam pelo impeachment de Fernando Collor no início dos anos 1990. Em outra perspectiva, o passado ditatorial também pode ser evocado por alegorias mais tensas e imersivas, como demonstra Rosane Kaminski ao analisar o curta-metragem Ressurreição (Arhur Omar, 1988). Na montagem do filme, os cadáveres remetem ao horror de uma sociedade alicerçada no mais indecoroso espetáculo midiático e explicitam o mal-estar de uma ditadura recente. As imagens de arquivo são colhidas da tragédia cotidiana dos jornais populares e nos conectam a uma experiência histórica brasileira mais imediata e brutal: a da tortura e repressão institucionalizadas pelo regime militar.

Outro levantamento de filmes sobre a ditadura brasileira está na pesquisa de Cristiane Gutfreind sobre a importância do "realismo político" na produção de documentários dos anos 2000. E sobre como o cinema atua na realidade da sua sociedade, sobretudo quando integra movimentos de reparação histórica que ganharam força com as indenizações das vítimas pelo Estado, as aberturas de arquivos políticos e a própria atuação da Comissão da Verdade. Realismo bem presente nos documentários biográficos, baseados em personagens cuja existência é legitimada pela história, e que constroem imagens contrapostas às narrativas das instituições oficiais, contribuindo, assim, para a (re)elaboração da memória e do saber histórico.

Dos documentários biográficos, Reinaldo Cardenuto analisa três obras que empreenderam narrativas de busca. Segundo o autor, as jornadas investigativas trazem um "cavoucar de si mesmo" diante de ausências pessoais e lacunas históricas, e por isso retratam o trânsito entre as histórias individual e pública. No filme Em busca de Iara (Flávio Frederico, 2013), o resgate da trajetória da familiar assassinada resulta no desfecho conciliatório, com uma dimensão pública algo romantizada da memória sobre as guerrilhas. Já em Diário de uma busca (Flávia Castro, 2011), tem-se o tom inconclusivo e aberto às leituras e representações nada monumentais da luta armada. Já a reflexividade em Os dias com ele (Maria Clara Escobar, 2013) expõe outra sorte de inquietações coma própria construção do documentário. De forma bastante clara, o autor explica como o filme se realiza na disputa por representações advindas do conflito entre a filha e o pai, e demonstra as complicadas negociações no próprio processo de construção da memória e da história.

Nas pesquisas de Carolina Aguiar e Ana Laura Lusnich sobre os regimes do Chile e da Argentina, a disputa pela memória é fator central. Os textos expõem a urgência e a denúncia nos filmes realizados durante essas ditaduras e as suas contribuições para combatê-las. No caso chileno, 
Carolina Aguiar analisa dois "filmes solidários", isto é, documentários de denúncia feitos por estrangeiros que expõem a repressão de Pinochet e as inquietações históricas e conjunturais dos próprios cineastas alemães e franceses envolvidos. Além da analogia aos campos de concentração alemães e ao apelo à unidade das esquerdas francesas, a solidariedade dos filmes consiste em revelar o horror ditatorial no extracampo da imagem, através das estratégias clandestinas, e até farsescas, para driblar o cerceamento e para desconstruir o autoelogio do regime chileno. Em relação à Argentina, Ana Laura Lusnich traz um conjunto delongas-metragens ficcionais produzidos durante a ditadura. $\mathrm{O}$ corte alegórico-metafórico destes traduz o "terrorismo de Estado" presente nas instituições políticas, militares, no poder econômico, nas entidades sanitárias e até na família de classemédia do país. A autora escrutina os enredos relativos aos momentos da produção dos filmes, e nos mostra como personagens, temas e o aspecto diegético permitem compreender os graus de capilaridade das práticas ditatoriais. Também expõe o papel de resistência do cinema em circunstâncias repressivas dentro de um contexto onde, mesmo sob a censura do circuito comercial, tais filmes foram exitosos ao representarem a opressão do regime militar e a cumplicidade da sociedade civil.

A disputa pela memória também é abordada noutra dimensão: a dos bastidores de projetos e políticas governamentais para o cinema. Ao estudar o longa-metragem Independência ou morte (Carlos Coimbra, 1972), Ignácio Dávila resgata relações de interesses entre cinema e Estado no sesquicentenário da Independência, quando se realizou um "filme histórico" para reforçar o ufanismo midiático do milagre brasileiro. $\mathrm{O}$ autor mostra a intenção do governo Médici de usar o cinema para fortalecer o presente associando-se ao passado pela atualização de monumentos pré-existentes, como, por exemplo, a literatura ufanista paulista dos anos 1920 e a iconografia de Pedro Américo. Nessa chave, a personagem de Dom Pedro, ligada aos temas "religião, nação e descendência" de um nacionalismo pregresso, evidencia o "deus, pátria e família" de uma pedagogia nacionalista que, pelo cinema, se atualizava no oximoro tradição-modernização.

A respeito da instrumentalização do filme histórico pela ditadura brasileira, Eduardo Morettin envereda, no capítulo que abre o livro, pela tentativa de dirigismo estatal para alavancar uma história oficial pelo cinema. A sua investigação com o fundo Embrafilme dá a ver a continuidade histórica entre períodos autoritários brasileiros, ao estudar um projeto de fomento reeditou, nos anos 1970, a prática estado-novista do Ince (Instituto Nacional de Cinema Educativo): a de pretender a chancela de historiadores para emplacar o estatuto de verdade aos filmes históricos. O artigo, porém, trata do papel do historiador na sociedade, ao mostrar a postura de Carlos Alberto Vesentini - consultor em um dos filmes do projeto irrealizado da Embrafilme. Vesentini expôs as tensões em encapsular ou mitificar personagens e eventos históricos na narrativa clássica ficcional. Ao invés da "chancela histórica", ele mostrou a potencialidade dialética do espaço de construção da memória, igualmente aberto a interpretações contrárias àquelas pretendidas pelo regime militar. Quanto ao mecenato oficial, a pesquisa de Margarida Adamatti fala de Gustavo Dahl, crítico e cineasta responsável pela distribuição comercial da Embrafilme no período Geisel. Em textos dos anos 1960 e 1970, a autora detecta a estratégia de Dahl para adequar sua luta pelo cinema nacional ao contexto repressivo. Se a cultura política "nacional-popular" forjou o engajamento cinemanovista dos anos 1960; 
${ }^{5}$ ESCOREL, Eduardo. A direita na tela: notas sobre um panfleto audiovisual que revê 1964 . Revista Piauí, edição 152, maio de 2019. Trata-se do filme 1964: $o$ Brasil entre armas e livros (2019). nos anos seguintes Dahl recorre a uma estética do silêncio em seus textos, conotando certa negação do político. Algo necessário para não confrontara ditadura e continuar a "ir ao povo", mas deslocando o político para o apelo estético e emotivo. Estratégia que aproximou o cinema nacional do público, e fez brigar pelo mercado ocupado pelo filme estrangeiro e disputando, assim, espaços para narrativas fílmicas da nossa memória nacional.

As perspectivas apresentadas no livro se baseiam nas disputas pela memória presentes, direta ou indiretamente, nos recortes temáticos e temporais; no trânsito entre a história pública e a memória individual nos documentários; nas representações da ditadura em obras ficcionais; na instrumentalização do passado para narrativas de poder; e nas estratégias de resistência em contextos repressivos. Todavia, apesar dos dois consistentes capítulos sobre Argentina e Chile, a presença de mais análises sobre as experiências ocorridas nesses países, e outros do "Cone Sul", tornaria a coletânea uma contribuição ainda mais inestimável para a compreensão da relação "história e audiovisual" acerca das ditaduras na América Latina. Outra ausência também sentida, no caso da ditadura brasileira, é de uma abordagem com filmes ligados a ações de reparação do Estado e/ ou acervos da repressão política. Documentários na linha de Reparem bem (Maria de Medeiros, 2012) e Retratos de identificação (Anita Leandro, 2014), por exemplo, seriam bem-vindos ao rol das análises. De toda forma, o livro é uma valiosa adição às pesquisas já existentes, e um pronto arsenal para enfrentamentos necessários, como o do cineasta Eduardo Escorel contra uma falaciosa produção que desrespeita fatos e experiência históricos - e tenta travestir de documentário uma peça de propaganda com pretensões didáticas, que se arvora à tarefa de impor "verdades nunca antes contadas". ${ }^{5}$

Olhar a história a partir das questões do presente não é ofício só do historiador. É, antes de tudo, tarefa cidadã atinente a todos e que envolve a salutar revisão da história para o enfrentamento de traumas e tabus da memória social edificada ao longo de décadas. Tratamos aqui da própria evolução da sociedade, medida pela sua capacidade de salvaguardar a história fundamentada em fatos comprovados, independentemente dos sentidos conferidos por diferentes narrativas históricas sobre as ditaduras. Em 2019 a disputa pela memória passa pelo incontornável combate ao negacionismo, no Brasil e no mundo, e pelo esforço de incorporar novas compreensões sobre a experiência histórica que nos trouxe até aqui. Algo muito bem exposto pelas pesquisas reunidas em $O$ cinema $e$ as ditaduras militares, ao mostrar as potencialidades do audiovisual em antecipar pautas e debates sobre os nossos passados traumáticos e em contribuir para a criação e transmissão de conhecimento histórico. Mais do que isso: o audiovisual como ferramenta para ajudar a entender quem somos, e qual o lugar queremos ocupar na história.

Resenha recebida em 30 de maio de 2019. Aprovada em 27 de julho de 2019. 